\title{
Guidelines for Value Management
}

To ensure long-term survival and development, Huawei must first go international, then go global. It must explore new domains and expand its development space. Expansion requires the support of a proper management system. Without such a system, expansion would end in vain and could also be very dangerous. If that is the case, it would be better not to expand at all.

As Huawei creates value for its customers, Finance plays the role of a value integrator. It turns the value created by capital, technology, and talent into the company's revenue, profits, and cash flow. It also performs the task of turning the effort of the entire workforce into hard cash. To fulfill its mission as a value integrator, Finance must establish a scientific, standardized, and highly efficient management system that is able to keep risks under control. Since 2007, under the guidance of IBM consultants, Huawei spent seven years successfully implementing its Integrated Financial Services (IFS) program. This transformation has reinvented Huawei's financial management system, making it on-par with those of world-class companies and effectively supporting Huawei's rapid business growth worldwide.

Research on theories and new sciences shows that all systems exist and develop on the basis of several major principles. These principles define the overall characteristics and paths of evolution for these systems. Similarly, Huawei's financial management system also evolves, transforms, and improves according to some basic principles. Summarizing and distilling

(C) The Author(s) 2019

W. Huang, Built on Value, https://doi.org/10.1007/978-981-13-7507-1_7 
these basic principles will help people gain a deeper understanding of the essence and rules of financial management. They will also help improve the initiative of management, reduce passiveness and blindness, and move the company from the realm of necessity to the realm of freedom.

This chapter elaborates on the guidelines and basic principles that Huawei's Finance uses for value management. These guidelines and principles are not doctrines, but a road map for financial management. What is important is that they provide the methodologies for understanding Huawei's value management.

\subsection{Huawei's Most Valuable Asset: An Enduring Management System}

\subsubsection{Management Is Key to Ending Reliance on Talent, Technology, and Capital, and Enabling the Company to Evolve from the Realm of Necessity to the Realm of Freedom}

Management is key to ending our reliance on talent, technology, and capital, and enabling the company to evolve from the realm of necessity to the realm of freedom. Effective management can enable us to build a platform that helps unleash the biggest potential of talent, technology, and capital. Talent is our most valuable asset, but when we still rely on talent, technology, and capital, our value assessment system is, to some extent, distorted. When this happens, we can't say we are free. Only when we no longer rely on these three elements can we make scientific decisions. The reason we drafted The Huawei Charter was to build a platform and a framework to unleash the potential of our talent, technology, and capital. (Ren Zhengfei: How Long Can Huawei Survive?, 1998)

We need to establish a sound system of management controls and the right policies to ensure our corporate strategy, policy, and culture are well-aligned. Built on this, we can fully delegate authority to managers at all levels, and create a vibrant, efficient, and stable environment where the company is both goal-oriented and value-driven, and at the same time have processes and policies to follow. (Source: The Huawei Charter, 1998)

Management and services are what concern Huawei's life and death. Talent, capital, and technology are not, as they can be acquired from outside sources. Management and services though cannot simply be copied. 
Only by relying on the joint effort of all our employees can we identify advanced management and service theories and apply them to our practices. Based on this, we need to build our own effective management and service system, and ensure that the system runs smoothly across the company and throughout our business processes. (Ren Zhengfei: Do Not Be a Temporary Hero, 1998)

The challenges we face in the future will not be related to technologies or products. Instead, they will likely be in basic research and innovation. The key to overcoming these challenges lies in our management. The biggest challenge we face right now is internal management - to build organizations, processes, and IT systems that can promptly adapt to market demands and meet customer needs. If such a management system is not in place, problems will arise as our company continues to grow. To avoid a decline and slackoff, we must constantly motivate our organization and maintain its vitality. While we should keep our organization under control at all times, we must not control it to the point that it loses vitality. What matters is a balance between motivation and control, and this balance must be constantly adapted according to changing dynamics. (Ren Zhengfei: Huawei's Opportunities and Challenges, 2000)

Huawei must go global. We can't remain content with just being a Chinese company forever. Staying this way will cause problems for us. What if the Chinese market becomes saturated in a few years? Our R\&D has been providing content services, exploring new fields, and developing new software to create more space for development. To increase our likelihood of survival, we must expand into overseas markets, and this process must be governed by a solid management system. Growth without the support of a solid management system can be very dangerous. If that is the case, it would be better not to expand at all. (Ren Zhengfei: Speech at the Training Session for Marketing Managers, 2002)

First, we need to manage employee conduct. Second, we need to implement an ownership system for processes at all levels. We also need to develop a code of conduct and rules for discipline and rewards, and define positional responsibilities. With these in place, process owners won't dare to slack off. Approaches, methodologies, and templates are what our oversight department needs to develop in order to provide professional and standardized guidelines. You can send them to business departments and allow them to establish their own oversight systems, but you need to assess and approve them. This approach is how we can truly link oversight and 
business operations. (Ren Zhengfei: Speech at a Briefing on Regional Oversight, 2007)

Western companies have developed their modern business management systems by fine-tuning approaches to scientific management over the last century. Built on the trial and error of countless companies, these systems are precious embodiments of human wisdom and represent a wealth for humanity. Huawei must be humble and systematically learn these management systems. Only with a modern business management system can our large-scale product innovation lead to business success. It is with this system that we are able to deliver results, accumulate and transfer knowledge and experience, and advance by stepping on the shoulders of giants. (Ren Zhengfei: Speech at the Awards Ceremony for Whiz Kids, Huawei Executive Office Speech No. [2014] 039)

Huawei's most valuable asset is its enduring management system, which uses the certainty of rules and systems to deal with uncertainty and help us succeed in this era of massive data traffic. (Ren Zhengfei: Speech at a Work Report on Corporate Quality, Huawei Executive Office Speech No. [2015] 067)

\subsubsection{Goal of Transformation: To Harvest More Crops and Increase Soil Fertility}

We adopt a committee-based decision-making mechanism on major issues. For execution- or project-level issues, we allow department heads or project leaders to make decisions. That's why we can make decisions quickly. (Ren Zhengfei: Speech at a Meeting with Trainees of the 10th Senior Management Seminar at Huawei University, Huawei Executive Office Speech No. [2011] 031)

We should constantly optimize our corporate governance structure and clearly define the company's authority delegation and oversight mechanism for each BG. This will ensure that BGs do not deviate from the company's overall strategy or operational rules as they forge ahead. We should improve our performance appraisal and incentivization mechanisms to better motivate BGs to expand effectively and ensure sustainable and profitable growth for the company. In this new era, we should establish more scientific management approaches by truly living our corporate values and implementing good policies and processes. In addition, we should strengthen oversight while gradually delegating authority, so as to move 
forward on both of these wheels. (Ren Zhengfei: Guidelines on the Analysis of the Business Environment and Key Business Strategies, Corp. Doc. No. [2012] 081)

We can only leave behind two types of legacies for our company: One is a management system supported by our management architecture, processes, and IT systems. The other is an employee management and incentivization mechanism. No one stays at a company forever. Even if someone stays with a company their whole life, they will eventually pass away, but management systems won't expire. A management system is enormously valuable and can exist for hundreds or even thousands of years. If it is being continuously improved by our managers, how much will our management system eventually be worth? So long as we survive in the marketplace, this system will play its role. If we go public one day, the value of the company will completely depend on the value of these two legacies. We therefore highly prioritize our processes. (Ren Zhengfei: Speech and Comments at the Strategy Retreat of the Business Process \& IT Management Department, Huawei Executive Office Speech No. [2012] 026)

Over the next five to ten years, the company will focus on logistical service transformation. We must strive to change our centralized management approach and give both responsibility and authority to field offices so that those closest to customers can call for support. Our goal is to change HQ's role from management and control to service and support, and build a modern company that meets modern needs. (Ren Zhengfei: Speech at a Meeting with the Representatives' Commission, Huawei Executive Office Speech No. [2013] 056)

During our future transformation, we need to emphasize that our goals are what matter most. Our goals are to harvest more crops, make strategic contributions, and increase soil fertility. We should cut back on anything that doesn't serve these goals. Our transformation is primarily intended to establish processes and systems that help create value for customers. Anything that does not serve this primary purpose should be streamlined. Our current processes are overly complex because we haven't fully understood our goals. A clear understanding of our goals will help us improve efficiency and develop outstanding people who are both diligent and courageous. Then over the next three to five years, we will make some progress in our management. (Ren Zhengfei: Heroes Are All Around Us-Speech at the Q4 Regional Presidents' Meeting, Huawei Executive Office Speech No. [2014] 086) 
We must have a yardstick in place to measure our management progress. Our goal is to harvest more crops. Representative offices that are seeing little growth in customer orders but are experiencing profit growth are making management progress. We need to examine what contributions they can make to the company and ask whether these contributions are random or sustainable. This will provide us with rough baselines that we can use to measure our management progress. (Ren Zhengfei: Speech at the Briefing on the Transformation Elite Team and Related Progress, Huawei Executive Office Speech No. [2015] 026)

Based on the integration of the LTC process, we determine that our goals are to achieve the consistency of inventory accounts and goods (CIAG) in stage one and the Five Ones ${ }^{1}$ in stage two of our transformation. Of course, we shouldn't limit our objective to the Five Ones - Five Twos are also fine. Why do we strive for one second? One minute, one hour, or one day would all be fine, as they are all ones. Our ultimate goal is to harvest more crops and increase soil fertility. We will discard anything redundant during our transformation process. (Ren Zhengfei: Speech at the Briefing on the Transformation Elite Team and Related Progress, Huawei Executive Office Speech No. [2015] 026)

Huawei has passed its chaotic period and is now moving towards standardized operations. We must learn to use new approaches, improve our understanding of strategies and tactics, and increase our capabilities in specific operations. This is our mission for this new era. Without the support of IT systems, we would become an organization without a history. If we rely only on people to remember what we have done, they may forget what they have done as soon as they get up from their desks. Now, with the support of both processes and IT systems, we will improve step by step. In part, we use the certainty of rules and systems to deal with any uncertainty to continue down the right path. In truth, we are already on the right path. We just need to keep pushing on. (Ren Zhengfei: Speech at a Work Report on Corporate Quality, Huawei Executive Office Speech No. [2015] 067)

\footnotetext{
1 "Five Ones": any PO from receiving to order generation in One day, any shipment preparation in One week, any product delivered at agreed location in One month, any software ready for download in One minute, and any site from delivery to customer acceptance in One month.
} 


\subsection{Business Plays a Leading Role and Accounting Plays an Oversight Role}

\subsubsection{When We Say That "Business Plays a Leading Role and Accounting Plays an Oversight Role", We Mean That We Do Not Focus Solely on Financial Returns on Investment}

We must stick firmly to our macro management approaches and systems, under which business plays a leading role and accounting plays an oversight role. When we say that "business plays a leading role", we mean that we optimally develop our business based on our goals and needs. When we say that "accounting plays an oversight role", we mean that managers at all levels must fulfill their financial management responsibility, implement effective project management, and enhance accounting and cost control. This is how we can strike a balance between development and control. (Ren Zhengfei: Key Points for Management, 1999)

When we say that "accounting plays an oversight role", we mean that Finance provides standardized services. During this process, accountants exercise oversight. Services need to be standardized based on plans, budgets, and costs. At the current stage, the internal audit team mainly manages exceptions, but they also manage daily routine. After that stage, processes must not be changed and the sole task of the internal audit team is to manage exceptions. Our internal audit team also needs to oversee our accounting team outside China. (Ren Zhengfei: Speech at a Briefing on Four Unifications and 2000 Work Plan of Finance, 1999)

When we say that "business plays a leading role and accounting plays an oversight role", we mean that business managers have decision-making authority and are responsible for their own decisions. They are also responsible for the growth and financial robustness of the regions within their purview. Finance needs to serve and oversee business. By fulfilling their oversight responsibility, Finance will ensure that financial data truly reflects actual business activities and will help business managers make correct choices and decisions. (Ren Zhengfei: Speech at a Briefing on Methods and Results of CFO Appraisals, 2011)

Business managers are the primary owners of operating risks and internal controls within their purview. Financial personnel are assistants to business managers at all levels. You're there to give advice and disclose risks. You are part of their team and must play your role. Finance and business are highly interdependent, so you can only achieve shared success 
when you grow together. If Finance does a poor job, business will suffer. (Ren Zhengfei: Speech at a Meeting with Financial Staff, Huawei Executive Office Speech No. [2011] 032)

Business plays a leading role and accounting plays an oversight role. I said this over a decade ago to criticize those who were driven only by financial returns on investment. By saying "business plays a leading role", I meant we need to earn profits through technological innovation, talent introduction, and market expansion. Accounting, as I see it, does not simply keep our books. It also carries out project accounting and other financial management activities. By saying "accounting plays an oversight role", I mean Finance provides services and support while fulfilling management and oversight responsibilities. (Ren Zhengfei: Speech at a Meeting with Financial Managers, Huawei Executive Office Speech No. [2012] 029)

\subsubsection{Accurately Recognizing Revenue, Accelerating Cash Inflows, Ensuring Visibility of Project Profits and Losses, and Managing Business Risks}

Accurately recognizing revenue based on actual business activities is the basis for robust business operations

Currently, IFS is the most important business transformation at Huawei. Its critical value to the company can be described as "accurately recognizing revenue, accelerating cash inflows, ensuring visibility of project profits and losses, and managing business risks". (Guo Ping: Respecting Professionalism and Doing Financial Work Well in 2009-Speech at the Annual Meeting of Finance on January 17, 2009, Improvement Issue No. $327,2009)$

We need to link customer contract information to procurement contract information to support the company's fine-grained management. Our IDS1 ${ }^{2}$ focuses on transactions, which has streamlined the Opportunity to Cash (OTC) and Procure-to-Pay (PTP) processes from end to end, optimized and delivered a series of processes and rules, built integrated IT systems, and integrated customer contract information with procurement contract information. These results have helped achieve business goals like fast and accurate billing and accurate revenue recognition. Based on this, we are now able to access data on financial performance, operating efficiency, and operating quality like order, shipment, revenue, and payment

${ }^{2}$ IDS: Integrated Deployment Solution. 
collection on our business fulfillment monitoring platform iSee. This has helped us accurately locate problems, take effective business management actions, and enable fine-grained management in business units at all levels. (Meng Wanzhou: IFS: Working with Business Teams to Comprehensively Improve the Capabilities of Financial Staff, Improvement Issue No. 407, 2012)

Sales revenue is one of the most important financial indicators that are used to measure the company's business operations and quality. Objective, accurate, and prompt revenue recognition is crucial for robust operations. All business units must strictly observe the company's policies, rules, and processes for sales revenue recognition to ensure company operations are compliant and robust. Those who falsely recognize revenue will be held accountable. The following are all punishable offences: Recognizing revenue in advance or postponing revenue recognition by falsifying delivery progress information or delivery documents, and hiding true business information. These are all serious violations of Huawei's Business Conduct Guidelines (BCGs) and may have a material impact on the company's financial statements. The company has zero tolerance towards such misconduct and will immediately handle any such cases that are discovered. Extra bonuses granted because of inflated revenue must be returned and employees and managers directly responsible for these intentional violations will be disciplined according to the BCGs. (Source: Resolution on Disciplining Those Who Have Falsely Recognized Sales Revenue, Finance Committee Resolution No. [2014] 016)

\section{We must strengthen our control and management of cash flow}

Emphasizing both sales revenue and profits is not enough. We also need to strengthen cash flow management. We may have good contract terms, high prices, and high profits on our books, but if customers make payments years later, we may run short of cash and drive the company into the ground. Therefore, it is critical to control and manage cash flow. (Ren Zhengfei: Speech at the Mid-year Market Conference, Huawei Executive Office Speech No. [2006] 036)

The purpose of sales is not only to secure orders or sign contracts. "Any order, no matter how exciting it is, must generate revenue. All revenue, no matter how large it is, must bring profits and cash flow." Otherwise, we will just be quenching our thirst with poison and will ultimately be walking towards our company's demise. (Source: Resolution on Designating Team Members of the Joint Committee of Regions for Promoting Contract Quality Improvement, EMT Resolution No. [2011] 029) 
Cash flow is a major issue, and is our life line. If we don't have money to pay salaries, employees will leave and we will lose the strategic accomplishments made over the past two decades. We have managed to build an organization through hard work. Once it collapses, what can we do then? We must pay attention to local financing and further develop our local financing team to disperse financing risks. (Ren Zhengfei: Speech at the EMT ST Meeting, 2012)

Project management is the basis for the company's business management

We must remain project-centered and improve our project operations management. This is how we will increase efficiency and profits over the next couple of years. We need to focus on three types of projects: customer, R\&D, and transformation projects, and establish a project operations management framework that includes projects, programs, and project portfolios. We need to develop a complete system that runs from "doing the right things" to "doing things right" to drive the company's organizational change from a pyramid, function-centered structure to a project-centered structure with functional departments playing an auxiliary role. (Guo Ping: Transform Continuously and Improve Field Operating Capabilities to Ensure the Company's Sustainable and Profitable GrowthSpeech at Huawei Annual Management Conference 2013, Huawei Executive Office Speech No. [2014] 020)

In the future, we will implement a project-based total budget system. Under this system, we will first deduct the company-borne expenses from project budgets, because the company spends money transferring resources to projects. The remaining budget will be given to projects, and with the money, project managers can buy resources from Supply Chain and services from $\mathrm{HQ}$. Project managers do not have to buy unnecessary resources. Functional departments do not have any budget pressure right now. As a result, they are not motivated to sell resources to projects. That is why we have a bloated organization at HQ. We must manage project plans and budgets. When a project is completed, we need to do project accounting to see if it has made or lost money. Project profitability is a key criterion for assessing a project manager's performance. (Ren Zhengfei: Remarks at a Meeting with Members of the Project \& Financial Management Enablement Program for High Potentials, Huawei Executive Office Speech No. [2014] 054)

Over the next five to ten years, we will gradually shift from a centralized management model to one that allows employees closest to customers to 
call for backup. Currently, we are tentatively shifting from functioncentered to project-centered operations. If we can truly delegate managerial authority to field offices and if back offices can provide better support services in five to ten years, we will be able to increase our response speed and our ability to meet customer needs. We will then survive the surging waves of massive data traffic. (Ren Zhengfei: Our Transformation Goals Are to Harvest More Crops and Increase Soil Fertility-Speech at the 2015 Huawei Market Conference, Huawei Executive Office Speech No. [2015] 016)

While shifting from a function-centered structure to a project-centered structure, we need to clearly specify how projects should operate and what management systems we should adopt, so that our project line is separate from our resource line. For sales and delivery projects on the front line, SDTs at all levels are our decision-making teams, and physical organizations at representative offices, regions, and HQ are our resource departments. Projects have budgets and resource departments provide resources, so that project teams can deliver to customers what contracts require. Under this operations management system, project operations, budget management, resource management, and project teams will all need to change to support the shift from a function-centered model to a projectcentered model. (Source: Minutes of the Work Report on the Project for Changing Function-centered Operations into Project-centered Operations, BOD Executive Committee Meeting Minutes No. [2015] 020)

\section{Controlling risks from a perspective of value management}

We need to guard against the operating risks arising from some possible high-risk customers, for example, carriers that may be acquired. We also need to strengthen our internal controls and auditing processes and systems, and conscientiously implement them to fend off corruption. We also need to pay attention to the possible impact of protectionism and further plan for and meet local manufacturing requirements. (Source: $2010 \mathrm{Key}$ Work Requirements, EMT Resolution No. [2010] 007)

Corruption and overstocking are the two biggest challenges the Consumer BG faces. I won't compromise on these two things. Overstocking even only once or twice may lead to our demise. I would rather take a longer time to meet consumer needs, rather than engage in overstocking. As consumer products become increasingly customized, overstocking will pose ever greater risks. (Ren Zhengfei: Be Bold at Work, Be a Humble Person, and Follow the Patterns of Consumer Products in the Pursuit of Maximum Growth and Success - Speech at a Meeting with the Key Employees of the Consumer BG, Huawei Executive Office Speech No. [2011] 014) 
Adopting a new business model is always risky. This requires us to establish a stringent control mechanism. (Ren Zhengfei: Guidelines on the Analysis of the Business Environment and Key Business Strategies, Corp. Doc. No. [2012] 081)

We need to summarize our past experience and determine our strategic goals for tomorrow based on where we are today. Over the past 25 years, Huawei has generally adopted a correct strategy. When the global economy was growing, we emphasized growth through economies of scale. As long as we operated at a large scale and won lots of contracts, we were able to dilute our fixed costs and generate profits. If our products were expensive at that time, would customers buy them? Of course not. Now though, our people are still doing the same thing. They focus too much on getting orders and contracts without considering their quality. They win contracts blindly as long as they can drive up sales. If we hadn't strengthened contract quality management, resolutely changed our strategic goals, and emphasized that we must be profit-oriented during the past two years, we would have been unable to have a meeting here today and most of you would probably have already been sent home. That's why over the past couple of years, we have emphasized that we focus on profits for managed services and consumer products and don't measure their sales revenue. This shift in KPIs is a kind of transformation. Of course, we still need to further transform our budgeting. Over time, we will see more change. (Ren Zhengfei: Why Can't Water from the Himalayas Flow to the Amazon River?-Remarks at the Work Conferences of the Latin America Region, Key Account Departments, and Carrier BG, Huawei Executive Office Speech No. [2014] 044)

A financial crisis could arise any time now. We must reduce long overdue inventories and long overdue accounts receivable (AR). (Ren Zhengfei: Speech at a Meeting with Employees of the Quality, Business Process \& IT Management Department, Huawei Executive Office Speech No. [2016] 094)

\subsubsection{How Can Financial Personnel Effectively Serve and Oversee Business If They Do Not Understand It?}

Financial personnel are not decision makers. Rather, you are there to give advice and oversee business. If you don't understand business, how can you effectively serve and oversee it? You need to meet reasonable business needs and provide valuable financial services. You should be able to identify whether business needs are real and reasonable. You need to effectively 
oversee business operations and help business managers grow. You must have your own judgment and cannot just blindly rely on what others are saying. (Ren Zhengfei: Speech at a Meeting with Financial Staff, Huawei Executive Office Speech No. [2011] 032)

Business departments take responsibility for all risks. Finance analyzes and reminds business departments of the risks. Business departments are responsible for growth, profits, and most importantly, for legal compliance. (Ren Zhengfei: Minutes of the Meeting with Staff of the Romania Accounting SSC, Huawei Executive Office Speech No. [2011] 021)

Regional and representative office CFOs are responsible for overseeing the quality of contracts in regions within their purview. They must dare to veto poor-quality contracts. This can help establish checks and balances between regional CEOs and CFOs. CFOs at all levels must participate in pre-sales contract reviews and must have the courage to veto poor-quality contracts. Contracts vetoed by CFOs must be escalated to a higher-level contract review team. The contract review team of the same level will no longer have the decision-making authority over the vetoed contracts. CFOs that can't handle this work must be replaced promptly. (Source: Minutes of the Report on the 2011 HI Performance Review, EMT Meeting Minutes No. [2011] 011)

$\mathrm{CFO}$ authority to veto contracts is primarily the authority to escalate contracts to an upper-level decision-making team. When CFOs voice a differing opinion about contract terms or business models, the contract decision-making team of their same level can no longer make decisions on the contract. In such cases, a decision needs to be made by a higher-level team. (Source: Minutes of the Report on Improving Contract Quality, EMT Meeting Minutes No. [2011] 012)

Our management must respect facts. Those who manipulate business data and commit fraud will be held accountable. (Ren Zhengfei: Minutes of the Report on the Opportunity to Order for 2017, EMT Meeting Minutes No. [2016] 021)

\subsubsection{Oversight Means Firm Commitment to Process Management}

Modern management systems are actually founded on distrust. If they weren't, we would not need process-based operations, authentication, or enhanced oversight. It's just that no one says this openly in the books. Although systems do not place trust in people, we are people-friendly 
when implementing these systems. There are always risks out there, but we cannot stop our processes for the sake of guarding against risks. Such a system at Huawei will help us constantly improve ourselves. (Ren Zhengfei: Remarks at a Meeting with Procurement Managers, 2000)

Financial policies must be developed centrally by the Finance Management Department. Regional offices cannot develop them. If regional offices want to add some additional provisions or notes, they must obtain approval from the Finance Management Department. (Ren Zhengfei: Speech at the Briefing by the Audit Department on Audit Projects in Latin America and South Africa, 2004)

Finance must oversee business operations while providing fast, accurate, secure, and standardized services to business departments. Standardized management is the basis for providing fast, accurate, and secure services to business departments. This is precisely the value that Finance can bring to business. (Ren Zhengfei: Building Finance into an Invincible Organization That Adapts Quickly to Our Business DevelopmentSpeech at the Training Class for Financial Managers in the European Region, 2005)

Huawei's management philosophy is like a cloud in the sky. Both internal and external factors, such as management philosophy, strategic requirements, and the industry environment, are the forces that push the company's operations forward. Rainwater from the cloud needs to be properly channeled to ensure accurate execution. The clond must turn into rain, and rainwater must flow along the proper channels, eventually reaching the sea. That's the water cycle. At Huawei, rainwater is our business activities, including financial activities. Financial oversight must be in place at key channel nodes, in order to ensure rainwater flows in the channels at a proper speed and with the desired quality. (Ren Zhengfei: Remarks at the Briefing on Finance Process Building, Huawei Executive Office Speech No. [2013] 091)

Financial oversight means firm commitments to process management. We must build oversight into every part of our processes. We must dare to expose problems and push for improvement. (Ren Zhengfei: Speech at a Meeting with Staff in Mauritius, Huawei Executive Office Speech No. [2013] 016)

Oversight is part of business. It is based on processes and realized in business practice. The majority of our oversight will be built into processes. Processes themselves are lines of defense, so if we have well-designed processes, we will already have an effective oversight system. (Source: Huawei's Oversight Philosophy, 2015) 


\subsubsection{Everything We Do Must Support Field Operations, Serve Business, and Contribute to Business Success}

The primary goal of establishing a management system is to increase operating capabilities of field teams. We need to learn from the US military's practices in the twenty-first century: On the front line are highly competent units that focus on goals and pursue success. At the back office is the decision-making center that sets the direction, develops strategy, and fully delegates authority. All competence centers have clear responsibilities, are targeted at operations, and form a joint support platform. This system is like a dragon, whose head moves flexibly to look for food or attack a target. Its highly developed bone systems are well-coordinated to ensure that the whole body moves to support any attack the head may start. (Guo Ping: Transform Continuously and Improve Field Operating Capabilities to Ensure the Company's Sustainable and Profitable Growth-Speech at Huawei Annual Management Conference 2013, Huawei Executive Office Speech No. [2014] 020)

"Everything we do must support field operations, serve business, and contribute to business success." This could become the slogan for our era of transformation. Within the next decade, we will implement a strategy of deploying highly competent elite teams with the support of a large platform and gradually separate resource management authority from command authority. The latter authority should be further delegated to field offices, which will allow for more flexible decision making and encourage more outstanding leaders to work in the field. Representative offices serve as profit centers and are responsible for results. Our command and decision-making authority should first be delegated to representative offices. Likewise, oversight authority should move to field offices as well. After several years of exploration and development in field offices, our subsidiary boards of directors have gradually matured in terms of compliance management, both internally and externally. These efforts have started to pay off, so we can begin piloting authority delegation to field business departments in certain countries. We need to allow representative offices to approve more contracts. This is what authority delegation is all about. Our workflows should be linked both vertically and horizontally. We must allow those who are closest to customers to call for support and ensure that the support they request will be provided. We must strive to improve contract quality, so that we can earn money promptly. Each project should have a CFO, who must participate in the end-to-end process from contract planning to contract closure. (Ren Zhengfei: Firm Belief and 
Strong Focus Lead to Greater Success-Speech at the 2016 Huawei Market Conference, Huawei Executive Office Speech No. [2016] 007)

All managers in field offices must focus on achieving success, giving functional departments the authority to manage things that are certain. All managers in functional departments should keep a close eye on field offices and urge their own departments to provide prompt and accurate services. Your appraisals will be based on the services you have provided to field offices. If field offices fail, you will have also failed. We must learn to find faults in success and identify the root causes of failure. People in ancient China had ritual rooms for self-reflection. Why can't we learn to reflect on our failure? Heroes can also emerge from failures. The faults of managers should not overshadow the efforts of their subordinates, as some of them might have done things that deserve praise. (Ren Zhengfei: Firm Belief and Strong Focus Lead to Greater Success-Speech at the 2016 Huawei Market Conference, Huawei Executive Office Speech No. [2016] 007)

\subsection{Using the Certainty of Rules to Deal WITH THE UNCERTAINTY OF RESUlTS}

\subsubsection{Setting Rules to Prevent Chaos}

Why did we implement the IFS Program in the first place? We hoped to use the certainty of rules to deal with the uncertainty of results. We are not sure about our company's future direction. It's impossible for us to know exactly where the company will be heading in the future. It's the entire society and our business environment - not we ourselves - that will shape the future of our company. We can't be too idealistic in deciding what our future will be like, but we can set rules that will help us prevent chaos as we move ahead. Therefore, the reason we implement IFS is to use the certainty of rules to deal with the uncertainty of results. Do we have to find an optimal form for the IFS program? I cannot bring everything good from other companies into Huawei. Even if I could, we may not be able to integrate those elements into Huawei. Can't we just learn from a good teacher? Even things we introduce from IBM may not be used directly. What is the best in the industry? I don't know what the best is. In fact, I don't think there is something that can be called the best. The thing that best suits our needs is the best for us. (Ren Zhengfei: Speech at a Meeting with the IFS Project Team and Staff from Finance, Huawei Executive Office Speech No. [2009] 004) 
We must set rules. If we use the certainty of rules to deal with the uncertainty of results, we will move forward faster. Take for example the Tokyo station. Although traffic volume there is huge, things are going fast, and both business management and oversight are extremely effective. The Tokyo station is seven storeys tall, with five for metro lines and two for high-speed trains. On each storey, dozens of trains are running. Escalators and lifts are used to connect different storeys. Trains are running at high speeds, but I have never seen people directly oversee them, and there are no collisions. This shows an ideal relationship between oversight and business. The high-speed trains and all the conveniences modern transportation brings are examples to be followed for business and internal controls. (Ren Zhengfei: Speech at a Meeting with the IFS Project Team and Staff from Finance, Huawei Executive Office Speech No. [2009] 004)

\subsubsection{Using the Certainty of Rules to Deal with the Uncertainty of Results for Major Processes, Allowing Flexibility at the Endpoints}

When it comes to major processes, we need to use the certainty of rules to deal with the uncertainty of results. However, we must have common interfaces for different processes and workflows. We need standardization at higher levels of the organization; otherwise, confusion could occur at lower levels. At the lower levels or endpoints, we can allow some flexibility. By endpoints, I mean our field teams. Things are changing fast out there, so we must allow flexibility and avoid being rigid. During transformations, we must emphasize that the interfaces of all outputs at representative offices must be absolutely standardized. However, representative offices can also have their own operations models and differences are acceptable. I think it is understandable to allow some flexibility at the endpoints. The bottom line is we must operate based on business needs. (Ren Zhengfei: Speech at a Meeting with the IFS Project Team and Staff from Finance, Huawei Executive Office Speech No. [2009] 004)

We should have stringent and well-established rules and systems that evolve over time. An important feature of these rules and systems is certainty. This is our understanding of the rules of the market and corporate operations. Rules change slowly. Therefore, we should use their certainty to tackle any uncertainty. (Ren Zhengfei: Our Transformation Goals Are to Harvest More Crops and Increase Soil Fertility-Speech at the 2015 Huawei Market Conference, Huawei Executive Office Speech No. [2015] 016) 
I think the most important part of our transformation is to establish rules for unified logistical services. We need to set standards for basic needs of different teams, and establish a platform that supports self-service at the front line. Doing so will enable field teams to self-manage, self-oversee, and self-improve themselves, thus forming a positive cycle. Based on such small management cycles at representative offices, logistical services for some general-purpose products can cycle through at the regional or corporate level, so that self-decision-making and self-oversight can be achieved. We also need to properly leverage contractors and reasonably assess and oversee them, to ensure our own capabilities are properly supplemented. (Ren Zhengfei: Speech at a Meeting with BCG Consultants, Huawei Executive Office Speech No. [2015] 039)

Three elements are necessary to guarantee Huawei's future success. First, we must have a strong leadership team that is open to criticism. Second, we should have stringent and well-established rules and systems that evolve over time. What are rules? Rules are about certainty, which we can use to tackle any uncertainty and define the boundaries for our development. Third, we need to have a large, hard-working, courageous, and dedicated team that is adept at learning. (Ren Zhengfei: Heroes Are All Around Us-Speech at the Q4 Regional Presidents' Meeting, Huawei Executive Office Speech No. [2014] 086)

\subsubsection{Using the Certainty of Rules to Deal with the Uncertainty of Execution}

The point of inviting consultants to Huawei is to help us establish rules and standards. The purpose of establishing a logistical service platform is to better support and serve the front line during their decision making. We need to use the certainty of rules to deal with the uncertainty of execution. In doing so, we will have clear rules and allow flexibility during execution, with oversight later on. (Ren Zhengfei: Speech at a Meeting with BCG Consultants, Huawei Executive Office Speech No. [2015] 039)

Contract managers mainly deal with certainties. They are responsible for efficiency and effectiveness following existing processes. Contract scenario experts deal with uncertainties. Their job is to minimize risks and gradually turn uncertainties into certainties. (Ren Zhengfei: Speech at the Report on How to Develop Contract Scenario Experts, Huawei Executive Office Speech No. [2015] 071) 
At the moment, some certainties are still managed as uncertainties, resulting in too much discussion, low efficiency, and wasted energy, and leaving too little time to deal with true uncertainties. (Ren Zhengfei: Speech at the Report on How to Develop Contract Scenario Experts, Huawei Executive Office Speech No. [2015] 071)

\subsection{Effectively Conducting Oversight While Further Delegating Authority to the Field}

\subsubsection{Centralized Authority Over Treasury, Accounting, and Auditing Management}

In the future, we will delegate authority to the field in every business. However, we retain treasury, accounting, and auditing management authority at HQ. The Consumer BG was set up not long ago but has developed into what it is today. It is a great accomplishment. In the future, these centralized platforms will contribute significantly to you, but of course, they will also restrict you in some ways. The Consumer BG has to generate profits and cash flow. It needs to grow as well. Don't pass this profit pressure down to lower-level departments, as that will result in fraud and lies, or people might press customers for money. We must respect facts. If you can't generate as much profit as expected, you can reduce your headcount. That will lower your costs. You can transfer your extra people to the Strategic Reserve, who can go to work in the field again after updating their skills. This is actually a scientific approach to development. (Ren Zhengfei: Speech at Consumer BG's Annual Meeting, Huawei Executive Office Speech No. [2017] 024)

The company has centralized authority over three lines of oversight: treasury, accounting, and auditing management. These three lines directly penetrate into every level of our organization and are transparent at every level. Members of our subsidiary board of directors need to develop integrated compliance oversight platforms at the subsidiary level so that risks can be identified and managed in business activities. For example, our understanding of market demand must not be one-sided. We must link market demand to customers' capacity to pay. Our public relations personnel must be sensitive to politics, promptly and correctly make overall assessments of the regions where business environments are deteriorating, and incorporate these assessments into market operations principles. 
Today, we haven't set ourselves apart from others in products, management, and business positioning. In countries where we should have made profits, we haven't achieved our profit goals and we are investing too much in high-risk regions. During performance appraisals, we need to separately look at the lawfulness of our financial reports and the reasonableness of our operations and incentive reports. This can help us truly turn our representative offices into profit centers. (Ren Zhengfei: Speech at the Meeting on Extension of the Company's Oversight and Management Control System, Huawei Executive Office Speech No. [2017] 041)

\subsubsection{Delegating Command Authority to the Field and Giving Field Commanders the Final Decision-Making Authority}

Huawei's governance model is not individual-centered, but team-centered. In general, authority should be delegated based on our business environment to cross-department committees or departments so that collective decision making and coordinated execution will be possible and accountability for decisions made will be shared. Currently, it is difficult to accurately delegate authority to particular positions, roles, or individuals. In addition, due to one-sidedness of individual decision making, role-based delegation will expose our organization to risks and cause conflicts and friction between different roles. (Ren Zhengfei: Speech at the Report on IBM's Authorization Practices and Huawei's Direction for Improvement, EMT Meeting Minutes No. [2008] 004)

At Huawei, we delegate decision-making authority over gross profits and cash flow to field operating teams. Within the scope of authorization, things can be done even without approval by representative offices. The goal of the military is to defeat enemies and our goal is to earn profits. Our Customer Centric 3 (CC3) face customers and aim to earn profits. Otherwise, all our management activities will be meaningless. (Ren Zhengfei: Who Calls for Artillery and How Do We Provide Timely Artillery Support?-Speech at the Awards Ceremony of Sales \& Services, Huawei Executive Office Speech No. [2009] 001)

We will delegate authority, exercise authority, and conduct oversight based on processes. This will help us break free of low efficiency and overstaffing caused by centralized governance and become a process-based organization driven by customer needs. (Ren Zhengfei: Who Calls for Artillery and How Do We Provide Timely Artillery Support?-Speech at the Awards Ceremony of Sales \& Services, Huawei Executive Office Speech No. [2009] 001) 
Our entire organization needs to be restructured to make mission command effective. The "Squad Leaders' Fight" does not mean that we leave squad leaders to fight alone. Rather, this model requires the support of the following:

- Division of responsibilities: Give tactical command authority to field operating teams. Executives and HQ should focus on developing corporate strategies, setting the company's direction, and allocating resources.

- Authority delegation: Separate administrative management authority from operations command authority, and properly delegate authority based on clearly defined rules and the preparedness of subordinates.

- Organizational structure: Remove or restructure field teams by function based on business needs.

- Resource distribution: Deploy tactical resources close to field operating teams and centrally allocate strategic resources to ensure rapid and effective response.

- Capability development: Comprehensively develop capabilities based on strategic needs.

- Processes: Business operations processes should focus on improving operating capabilities to adapt to a complex, volatile environment. Administrative management processes need to be rigorous and comprehensive.

- Information systems: Build an interconnected information environment to allow commanders at all levels to get whatever information they need anytime and anywhere to complete a task and develop a common understanding of the operating environment.

(Ren Zhengfei: Speech at a Briefing on the Takeaways and Challenges for Huawei Relating to the "Squad Leaders' Fight", Huawei Executive Office Speech No. [2014] 078)

As a traditional saying in China says, people are born good. Some say this theoretically is the reason there is often a lack of authority delegation and oversight in China. In the West, however, systems are used to keep people under control. The weakness of such systems is that they are too standardized, even at their most basic levels. At Huawei, we need to have less stringent decision-making processes at our most basic level and avoid the rigidity of Western systems. How? Where do we intend to tighten our control? We need to identify the critical points. Below these points, the field will be allowed to command operations. Above these points, reporting 
must be standardized. I think that we need to give our field teams more authority to decide on how they operate and how they deal with the results of operations. (Ren Zhengfei: Rigorous, Well-ordered, and Simple Management Is Crucial for Huawei to Scale New Heights, Huawei Executive Office Speech No. [2014] 028)

During organizational transformation, the ultimate command or decision-making authority needs to be clearly delegated. I agree that there can be many different types of decision-making authority, but what I mean here is the "ultimate" decision-making authority. BGs are sales-revenueoriented, while regional offices are profit-oriented. I believe that business decision-making authority should be given to regional offices. BGs should focus their efforts on building up resources, developing strategies, and taking part in operations. In order to increase sales revenue, BGs should find ways to persuade field commanders to adopt their points of view. I tend to agree that the Consumer BG holds the decision-making authority over its own business. For all other businesses, however, decision-making authority rests with regional offices. (Ren Zhengfei: Speech at a Briefing on the Takeaways and Challenges for Huawei Relating to the 'Squad Leaders' Fight”, Huawei Executive Office Speech No. [2014] 078)

When giving the ultimate decision-making authority to field commanders, it is important that we do not allow BGs or the Strategic Reserve to do what field commanders are supposed to do. If you do not think field commanders are up to the job, you can redeploy them and appoint new ones. However, the command authority should still remain with the field. In addition, I think we should delegate the decision-making authority on operational matters to subsidiary boards of directors. In the past, approval was made by HQ. But HQ cannot handle all approval requests. What kind of decision-making authority HQ should have? Decisions on solutions. Our experts have decision-making authority over solutions. When it comes to execution, however, the decision-making authority should rest with the field. Regarding the oversight over decisions made in the field, subsidiary boards of directors have a role to play. (Ren Zhengfei: Speech at a Briefing on the Takeaways and Challenges for Huawei Relating to the "Squad Leaders' Fight", Huawei Executive Office Speech No. [2014] 078)

This is what our transformation is about: laying the foundation for delegating more authority to the field. That is why we aim to streamline our LTC process over the next three to five years, and are striving to achieve the CIAG and Five Ones. Our subsidiary boards of directors are the oversight system of the company in the field. When they have the required 
oversight capabilities, we can delegate authority to our field command centers. (Ren Zhengfei: Speech at the Oath-taking and Awards Ceremony of the Transformation Elite Team, Huawei Executive Office Speech No. [2015] 047)

\subsubsection{Moving Oversight to the Field While Delegating Authority to the Field}

At HQ, we should streamline our organization and keep our processes simple. We should reduce direct command and remote control from HQ, move command centers to field offices, and give field teams the authority to perform their own planning, budgeting, and accounting. This means we are delegating the management and sales decision-making authority to field offices. Field offices need to have more tactical mobility to flexibly deal with changes in actual situations. Back offices need to step up their efforts to provide services based on plans and budgets and oversee the exercise of delegated authority through accounting. This can make sure field teams have the authority they need to get the job done and HQ doesn't need to worry about the authority being abused. (Ren Zhengfei: Speech at the UK Representative Office, Huawei Executive Office Speech No. [2007] 027)

We need to quickly establish a top-down oversight system that is independent of local offices. We can add independent directors or supervisors to our subsidiary boards of directors as oversight personnel. They can be non-Chinese. We need to optimize the governance structure of our subsidiaries and strengthen our oversight mechanism as we delegate authority to the field. (Source: Resolution on Setting Roles of General Managers and Board Directors in Subsidiaries Outside China, EMT Resolution No. [2008] 004)

Heads of business departments are the owners of oversight. We first need to make it clear that process owners are responsible for business selfchecks, internal controls checks and assessments, and delegation system building. The Business Controls Department must not take the job of business departments. We must avoid such a situation where business owners don't care about oversight but oversight personnel are very active. This won't resolve issues. As business departments are not doing their job in a standardized manner, the Business Controls Department is there to help them standardize, ask process owners to fulfill oversight responsibilities, and through internal controls checks and assessments, encourage 
heads of business departments to be responsible for business within their own purview. The Business Controls Department has the authority to assess business departments, evaluate their managers, and even demand the removal of managers from their positions when necessary. (Ren Zhengfei: Speech at a Briefing on Regional Oversight, 2007)

It is necessary to build an effective auditing and oversight system during our transformation from a centralized governance model to a decentralized governance model in which authority is fully delegated and checks and balances are in place. (Ren Zhengfei: Staying Customer-centric, Inspiring Dedication, and Persepering Are Key to Our Success-Speech at the 2010 Huawei Market Conference, Huawei Executive Office Speech No. [2010] 002)

Oversight naturally conflicts with efficiency. We could let things pass quickly and examine what happens afterwards. We could also exert controls before things happen and ask business departments to explain them clearly before they can be passed. The approach we choose depends on our own judgment and understanding of the risks we face. (Ren Zhengfei: Minutes of the Meeting with Staff of the Romania Accounting SSC, Huawei Executive Office Speech No. [2011] 021)

We need to give more authority to the teams working closely with customers. Only such flexible strategies and tactics can increase customer satisfaction, help us succeed, develop managers, and improve business performance. When we delegate authority to the field, we also need to move our oversight to the field. (Ren Zhengfei: Building a Highly Competitive Team - Speech at the Q3 Regional Presidents' Meeting, Huawei Executive Office Speech No. [2013] 093)

Business departments oversee their own exercise of authority throughout business processes, whereas auditing personnel oversee process activities. This can ensure that exercise of authority is meaningful and reliable. (Ren Zhengfei: Building a Highly Competitive Team-Speech at the Q3 Regional Presidents' Meeting, Huawei Executive Office Speech No. [2013] 093)

Business managers are fully responsible for employee education and internal controls. Those who are not comfortable fulfilling these responsibilities will have to be transferred to operational positions. Business managers should perform well in employee education. This includes local managers educating local employees. We need to ensure managers fulfill their responsibilities of managing themselves, their subordinates, and their internal controls, and properly match authority with responsibilities for 
typical high-risk positions. We also need to implement key internal controls in our consumer business, delivery, sales, and enterprise business to effectively increase internal controls maturity. (Ren Zhengfei: Speech at a Briefing on the Progress of Large-scale Elimination of Corruption, Huawei Executive Office Speech No. [2014] 010)

\subsubsection{Oversight Is the Means to Our End Goal: Business Success}

We will focus on profits during our performance appraisals. Representative office managers should understand management, finance, and operations. They should also continuously improve internal management and reduce operating costs. We aim to establish a management model under which business plays a leading role and finance plays an oversight role at account departments and representative offices. While focusing on profit-centered performance appraisals and fine-grained management, our financial reports must be fact-based and must not be overly optimistic or pessimistic. Finance must provide support to business. (Ren Zhengfei: Speech at the Report by the BT Account Department and the UK Representative Office, Huawei Executive Office Speech No. [2007] 015)

We must gradually change HQ from a management and control center to a support and service center that also performs oversight functions. We need to develop capabilities that enable the front line to drive back offices. We need to plan and make a shift from centralized management and control to delegation of operations authority to entry-level operating teams, ensuring our command centers are as close to our customers as possible. We need to help organizations at all levels become profit centers that reflect their own business characteristics. (Source: Resolution on the EMT's Priorities and Management Approaches from 2007 to 2009, EMT Resolution No. [2007] 012)

We will continue delegating authority to managers at all levels. What are the primary responsibilities for all managers at Huawei? The first responsibility is to create value. The second responsibility is to implement effective oversight. We have delegated authority to you, so you must help us manage the business that is in your charge. If you simply let corruption occur or turn a blind eye to it, we will consider you unqualified for your job, and you will no longer be allowed to serve as a manager. If you exercise strict controls against corruption, your people will work hard with you to earn and share more bonuses. You, as a manager, will grow from this 
and your team will grow too. If you fail to conduct oversight, we cannot delegate authority to you, and you will be replaced by someone else. (Ren Zhengfei: Speech at a Meeting with Trainees of the 10th Senior Management Seminar at Huawei University, Huawei Executive Office Speech No. [2011] 031)

We need to further delegate authority to the field, as this can help us seize opportunities. Our HQ should mainly play service, support, and oversight roles to better support the field in serving customers and controlling risks. (Ren Zhengfei: Focusing on Strategy and Streamlining Management, Huawei Executive Office Speech No. [2012] 041)

Internal controls teams need to go out to the field and work closely with field teams to ensure efficient operations and appropriate oversight. Engineering inspection teams are currently tasked with combating widespread corruption. Internal controls teams need to work with engineering inspection teams to develop policies and methods that ensure scientific oversight. The purpose of oversight is to ensure smooth business operations. Oversight is the means to our end goal - business success. (Ren Zhengfei: Speech at a Meeting with Financial Managers, Huawei Executive Office Speech No. [2012] 029)

Trusting employees doesn't mean we don't need oversight. Oversight doesn't mean we don't trust employees. (Ren Zhengfei: Building a Highly Competitive Team-Speech at the Q3 Regional Presidents' Meeting, Huawei Executive Office Speech No. [2013] 093)

The ultimate purpose of establishing an oversight and accountability mechanism is to prevent corruption, support effective business operations, and achieve business success. (Source: Minutes of the Report on the Charter for Building an Oversight and Accountability System, EMT Meeting Minutes No. [2014] 023)

Oversight personnel should be well aware that we have been solving problems as we move forward, rather than stopping to solve all our problems before moving on. Huawei would have stopped moving forward a long time ago if we did that. Therefore, we still emphasize solving problems as we move forward. We must not stop moving on because of corruption or ignore corruption in order to develop. The purpose of establishing an oversight system is to ensure the company's long-term development. (Xu Zhijun: "Cure the Disease and Save the Patient": Let Our People Start Afresh and Do Their Jobs Without the Weight of the Past on Their Shoulders, Huawei Executive Office Speech No. [2015] 064) 


\subsection{Streamlining Our Organizations and Processes to Create Value for Customers}

\subsubsection{Simplicity Is Key: Standardizing and Streamlining Routine Management}

To ensure Huawei's long-term survival and development, we must standardize our procedures. Foreign companies have scientific procedures in place for every payment they make. Why don't we learn from them? When standardized procedures are running smoothly, our finance system will become an open system and you will have more freedom rather than more constraints. (Ren Zhengfei: Speech at a Meeting with Financial Managers, 1995)

The primary goal of our management transformations is to increase efficiency and harvest more crops. During this process, we must also integrate our processes from end to end to streamline management. So long as our 150,000 employees stay united, our value management system is basically correct, and we continue to optimize and streamline our management, we will be a highly competent company. I believe that in five years, we will catch up with today's Ericsson in terms of management. What do we need to do right now? We need to implement management transformations to mobilize our employees. (Ren Zhengfei: Speech at the Report on the Integrated Management Transformation in Small Countries, Huawei Executive Office Speech No. [2014] 062)

We need to establish standardized and simplified shared services centers. How can our IT systems support our strategic command and delegation system? How can we implement a process ownership system? It's harder than just pressing a button and giving orders. We have to think about who will be responsible for oversight, statistics, and testing. The purpose of transforming our shared services centers is to make them simpler and more standard and their services easier to use. Personnel in our Quality, Business Process \& IT Management Department must not always pursue innovation. They must not make our processes too complicated. The purpose of any of our transformations is to harvest more crops and increase soil fertility. Transformations that do not serve this purpose are redundant and should be stopped. (Ren Zhengfei: Building High-Quality IT Systems Using Advanced Software Packages from Europe and the USSpeech at a Work Report by the Quality, Business Process of IT Management Department, Huawei Executive Office Speech No. [2015] 010) 
We should allow those who are closest to customers to call for support. Simplicity is key. Our authority must be delegated level by level, and our management must be standardized and streamlined. We should spend less time on meetings, simplify our appraisals, and have fewer examinations. We should not manage our employees as if they were students, let alone allow examination scores to impact their compensation. Our energy should mainly be focused on harvesting more crops and our appraisals should be based on contributions. (Ren Zhengfei: Our Transformation Goals Are to Harvest More Crops and Increase Soil Fertility-Speech at the 2015 Huawei Market Conference, Huawei Executive Office Speech No. [2015] 016)

Stable processes should be gradually standardized and streamlined. This can increase our capability to provide services promptly, and cut period and management costs. Issues of uncertainty should be transferred to departments responsible for miscellaneous issues. (Ren Zhengfei: Our Transformation Goals Are to Harvest More Crops and Increase Soil Fertility-Speech at the 2015 Huawei Market Conference, Huawei Executive Office Speech No. [2015] 016)

Strategic Reserve training needs to be scenario-based and focus on practice. The Transformation Project Team and Huawei University must collaborate to rotate golden seeds and let them unleash their potential. Both are required to identify several scenario types and develop tailored templates and case studies. This will provide representative offices with a full set of standardized methods to handle any scenario they may encounter. Strategic Reserve training needs to be scenario-based. There is no urgent need to train people for all scenarios. If someone understands one scenario, they will likely be able to understand others more easily. (Ren Zhengfei: Speech at the Briefing on the Transformation Elite Team and Related Progress, Huawei Executive Office Speech No. [2015] 026)

Our management needs to be standardized and streamlined in order to increase efficiency. Process owners need to promptly and accurately provide services, and quickly check relevant issues based on simple and standard processes without exercising excessive oversight. We have told the Consumer BG repeatedly that they need to make simple and standardized products that are maintenance-free during their lifecycles. Our aim should be to make the device manufacturing process similar to printing money. Similarly, their management needs to be standardized and streamlined with clear instructions like a high-speed railway. Why do we need to have so many checkpoints? It's really unnecessary. We must 
increase efficiency. HQ must provide services to field offices, and slash the number of meaningless checks. Our accounting system is like a sieve that allows most grains to pass through unhindered. Only one or two grains are caught by the sieve. Those grains represent issues that need to be reported and addressed. Currently, in some parts of our processes, information is flowing even more slowly than physical goods, which indicates that there are a lot of internal obstacles. If a manager is incapable of doing their job well, we should replace them with someone more capable as soon as possible. This is what the process ownership system is all about. (Ren Zhengfei: Speech at a Meeting with the Managerial Control Elite Team, Huawei Executive Office Speech No. [2015] 060)

In the future, we will set standard prices for standard products, beginning with boxes. Things that are uncertain - including customs clearance, engineering, and delivery - should be taken care of by representative offices. Land and sea shipment expenses will be allocated to beneficiary departments based on the amounts shipped. This mechanism will simplify appraisals, help people in remote markets, and allow the company to have less intermediate links. We currently have hundreds of different prices for the same equipment, because we factor expenses such as shipment and customs clearance into the prices. The pricing is so complex that representative offices cannot do it. As a result, the job has to be shifted back to HQ. We should continue to simplify the process. We will reduce headcount in field offices and at the same time streamline management at functional departments in back offices. (Ren Zhengfei: Speech at the EMT ST Meeting on January 25, 2016, Huawei Executive Office Speech No. [2016] 054)

Our business is growing, and our global presence is expanding. In spite of established processes and systems, our oversight still cannot be perfect all the time. Therefore, we still require self-discipline from our managers and employees to lower management costs. We also need to identify, select, and develop new managers in great numbers. To become outstanding managers, you need to create value and prevent problems through effective management, governance, and internal controls. The more systematic and process-driven we are, the more conscientious we need to be. This is similar to the relationship between the rule of law and religious belief in Western countries. We have established systems, but faithful adherence is necessary to ensure compliance. Can you imagine how much it would cost if we had to establish different layers of oversight for every single possibility? (Ren Zhengfei: Speech at the Huawei Market Conference on January 11, 2017, Huawei Executive Office Speech No. [2017] 007) 
Functional departments at back offices should provide capabilities that are specialized enough to satisfy different needs. These capabilities should also be made easily accessible to field offices. Field offices should be given the authority to orchestrate these capabilities. This is similar to the Chinese online doctor consultation platform "Hao Yisheng" ("Good-Doctor"), which uses utilization rates (like data traffic) as a standard for assessing departments that provide services. If the capabilities of certain departments are not utilized often, it may mean that they are not urgently needed. If this happens, we will first enhance departments who face greater demand, the same way we deal with spikes in data traffic. Then we should look at the workload of each employee and determine promotions accordingly. If a department's capabilities are rarely used, its headcount should be reduced. (Ren Zhengfei: Speech at a Carrier BG Briefing on the Progress of Three Cloud 2.0, Huawei Executive Office Speech No. [2017] 018)

To streamline processes and make them transparent, you need to begin with their source. If the source data is not accurate, data in the downstream may not be accurate, either. We must have standards in place for the introduction of new products. We need to consider whether products are manufacturable, deliverable, easy to maintain, or even maintenancefree before we begin developing them. How can we ensure that the new products we introduce meet our standards? The product acceptance template is like a sieve. Our R\&D has to test things through the sieve. Things that can't pass through the sieve must not be produced. This will force our R\&D to improve. Our R\&D personnel need to learn these standards well and early on, so more of their work will pass through the sieve. They have to standardize their own work using your template. If they think there are issues with your template, they can discuss with you and together you can make improvements. (Ren Zhengfei: Our Aim Is to Achieve High QualitySpeech at a Tour to the Songshan Lake Factory, Huawei Executive Office Speech No. [2017] 036)

\subsubsection{Any Department or Process That Doesn't Create Value for Customers Is Redundant}

Managers at all levels must focus their efforts on creating value and improving business. They should continuously improve their business capabilities, increase service quality, reduce operating costs, streamline processes, optimize organizations, and reasonably reduce headcount. These initiatives will allow our company to hone our competitive edge and 
improve our extensive relationships with customers. (Ren Zhengfei: Minutes of a Talk at the Xinsheng Building, 2012)

One goal of our transformation is to harvest more crops, including sales revenue, profits, high-quality delivery, efficiency improvements, the CIAG, and the "Five Ones". The other goal is to increase soil fertility, which includes strategic contributions, customer satisfaction, and effective risk management. Processes and systems that cannot directly or indirectly contribute to these two goals should gradually be streamlined. Only by doing so can we maintain our competitive advantages while remaining customer-centric. (Ren Zhengfei: Our Transformation Goals Are to Harvest More Crops and Increase Soil Fertility-Speech at the 2015 Huawei Market Conference, Huawei Executive Office Speech No. [2015] 016)

We must learn a lesson from the sinking of the Vasa warship. ${ }^{3}$ Warships are intended for battle, so any ornamentation is unnecessary. During our transformation, we must avoid taking unnecessary actions and making processes complex. The purpose of our transformation is to create value for customers. Departments, processes, and personnel that cannot directly or indirectly create customer value are redundant. We must keep this purpose in mind while streamlining our organizations and processes. (Ren Zhengfei: Our Transformation Goals Are to Harvest More Crops and Increase Soil Fertility-Speech at the 2015 Huawei Market Conference, Huawei Executive Office Speech No. [2015] 016)

The Regions Management Department should arrange for employees to study Huawei Executive Office E-mail Speech No. [2015] 016 Our Transformation Goals Are to Harvest More Crops and Increase Soil Fertility. Managers are required to write takeaways from this speech, list the problems that exist in their departments, and formulate plans on how they can solve them. They must avoid empty talk. Processes that don't help us harvest more crops or increase soil fertility are redundant, and must be eliminated. In some parts of our processes, information is flowing even more slowly than physical goods, indicating there are too many check points and our HQ is too bloated. So we need to reduce the number of managers and increase the number of experts. HQ managers who don't have much work to do can be transferred to the Strategic Reserve and gain field experience. Managers at HQ must have field experience and must

\footnotetext{
${ }^{3}$ The Vasa is a retired Swedish warship built during the early seventeenth century. The ship was richly decorated, a symbol of Sweden's "great power period”, but was also unstable and top-heavy. This lack of stability resulted in the Vasa sinking minutes into its maiden voyage.
} 
have served as project managers. As our organization gradually matures, we must remove duplicate processes and work, minimize the amount of work that creates no real value, and streamline our processes. In the next couple of years, we should fast-track the promotions of hundreds of outstanding project managers. They will serve as role models for other managers. (Ren Zhengfei: Minutes of the Briefing on the Progress of Differentiated Appraisals for Regions, Huawei Executive Office Speech No. [2015] 050)

Due to a lack of clear transformation goals, we made our management system over-complicated, added many unnecessary procedures, and employed tens of thousands of new staff. Now we need to make things simpler and gradually downsize. We have set a goal for our transformation, which is to harvest more crops. Anything that doesn't help us harvest more crops is meaningless. Any process, department, or employee that doesn't help us harvest more crops is redundant. That's the principle we should follow when we seek to streamline management. Of course, strategic investment in projects that increase our soil fertility will also enable us to harvest more crops. As we follow that principle, there'll be fewer loopholes in our system, our processes will run faster, and we'll be able to reduce our headcount more rapidly. We shouldn't overemphasize risks or set up too many risk control points for our processes. One representative office once held quite a few meetings over a matter worth 10 yuan. How much did these meetings cost? (Ren Zhengfei: Speech at a Meeting with the Managerial Control Elite Team, Huawei Executive Office Speech No. [2015] 060)

When we sent out the article Is the US Military Still Capable of Fighting a War as a Huawei Executive Office E-mail, I wrote a little introduction, where I said, "A soldier's responsibility is to achieve victory. Making sacrifices is simply a mindset." Becoming a general is not just about enduring hardships. You also have to contribute. Learning must be well-targeted as well. What is the use of a bellyful of knowledge without the ability to create value? A process, department, or person that puts no food on the table is redundant. They should all be cut. (Ren Zhengfei: Generals Are Born of Battle-Speech at the 2015 Project Management Summit, Huawei Executive Office Speech No. [2015] 118)

We should stay focused during our transformation and IT system development. This means that we should reduce the number of our transformations and must not have too many IT systems. For every new segment or checkpoint we add to our processes, we must eliminate two existing ones. Processes should serve our operations and help us harvest more crops. Are underused processes redundant? If a process is streamlined day by day, 
some people might complain. You should go and talk with them and check whether their requirements can be integrated into other processes. Of course, we can't simply eliminate individual processes, as that might result in breakpoints and conflicts, and eventually failure. (Ren Zhengfei: Speech at a Meeting with Employees of the Quality, Business Process \& IT Management Department, Huawei Executive Office Speech No. [2016] 094)

Open Access This chapter is licensed under the terms of the Creative Commons Attribution-NonCommercial-NoDerivatives 4.0 International License (http:// creativecommons.org/licenses/by-nc-nd/4.0/), which permits any noncommercial use, sharing, distribution and reproduction in any medium or format, as long as you give appropriate credit to the original author(s) and the source, provide a link to the Creative Commons licence and indicate if you modified the licensed material. You do not have permission under this license to share adapted material derived from this chapter or parts of it.

The images or other third party material in this chapter are included in the chapter's Creative Commons licence, unless indicated otherwise in a credit line to the material. If material is not included in the chapter's Creative Commons licence and your intended use is not permitted by statutory regulation or exceeds the permitted use, you will need to obtain permission directly from the copyright holder. 